\title{
PERANCANGAN SISTEM INFORMASI PENERIMAAN DAN PENGELUARAN DONASI BERBASIS WEB MENGGUNAKAN PHP \& MYSQL (Studi Kasus Pada Lembaga Karawang Peduli)
}

\author{
${ }^{1}$ Sofari Hanifah, ${ }^{2}$ Wawan Kusdiawan, M.Kom, ${ }^{3}$ Dedi Supriadi, S.E., M.M \\ E-mail : ${ }^{1}$ sofarihanifa1855@gmail.com, ${ }^{2}$ wawankusdiawan8@gmail.com, \\ 3dedidevan9@gmail.com
}

\begin{abstract}
Abstrak
Sofari Hanifah. Perancangan Sistem Informasi Penerimaan Dan Pengeluaran Donasi Berbasis Web Menggunakan Php Mysql (Studi Kasus Pada Lembaga Karawang Peduli). Dibimbing oleh Wawan Kusdiawan dan Dedi Supriadi.

Tujuan penelitian pada Lembaga Karawang Peduli untuk merancang sistem informasi penerimaan dan pengeluaran donasi berbasis web sehingga dapat mempermudah, mempercepat dan mengurangi tingkat kesalahan, kekeliruan dalam memasukan data penerimaan dan pengeluaran donasi. Metode pengembangan sistem yang digunakan yaitu System Deveploment Life Cycyle (SDLC) Waterfall. Menganalisis dan merancang permasalahan dengan menggunakan Object Oriented Analysis (OOA) dan Object Oriented Design (OOD) dan Object Oriented Programming (OOP). Menggunakan bahasa pemrograman PHP, XAMPP dan MySQL sebagai database manajemen sistem. Menggunakan Unified Modeling Language (UML) diagram yang terdiri dari use case diagram, sequence diagram, activity diagram dan class diagram. Hasil aplikasi yang dirancang dapat mengurangi terjadinya kesalahan dalam penginputan data, memberikan kemudahan akses bagi donatur dan adanya keterbukaan informasi keuangan terkait pemasukan dan pengeluaran donasi.
\end{abstract}

Kata Kunci : Penerimaan, Pengeluaran, System Deveploment Life Cycyle (SDLC) Waterfall, Web, OOP

\section{ABSTRACT}

SOFARI HANIFAH, Design of a Web-Based Donation Revenue and Expense Information System Using PHP Mysql (Case Study at Karawang Care Institute). Supervised by Wawan Kusdiawan and Dedi Supriadi.

The purpose of the research at the Karawang Peduli Institute is to design a web-based donation revenue and expenditure information system so that it can simplify, speed up and reduce the level of errors, errors in entering data on revenue and expenditure donations. The system development method used is System Waterfall Life Cycyle (SDLC) Waterfall. Analyze and design problems using Object Oriented Analysis (OOA) and Object Oriented Design (OOD) and Object Oriented Programming (OOP). Using the PHP, XAMPP and MySQL programming languages as a database management system. Using Unified Modeling Language (UML) diagrams consisting of use case diagrams, sequence diagrams, activity diagrams and class diagrams. The results of the application are designed to reduce the occurrence of errors in data input, provide easy access for donors and the disclosure of financial information regarding donation income and expenditure.

Keywords: Revenue, Expenditure, Waterfall Life Cycyle (SDLC) System Deveploment, Web, OOP

Jurnal Interkom: Jurnal Publikasi Ilmiah Bidang Teknologi Informasi dan Komunikasi

Volume 14 Nomor 03 Bulan Oktober - Tahun 2019 


\section{Pendahuluan}

Perkembangan pesat teknologi informasi yang tumbuh saat ini menimbulkan implikasi yang sangat luas pada segala aspek dalam kehidupan manusia dengan waktu yang relatif singkat. Terutama dibidang komputer dan komunikasi telah mengubah paradigma kehidupan manusia. Keunggulan tekhnologi bahkan dapat menggantikan posisi manusia sebagai alat didalam melakukan sebuah pekerjaan. Kegiatan pengolahan data adalah kegiatan yang dilakukan secara rutinitas yang biasa dilakukan oleh sebuah instansi atau perusahaan. Perkembangan dan pemanfaatan tekhnologi informasi terutama dalam pemanfaatan tekhnologi komputer juga menjadi perhatian dari kalangan instansi (Darmawan, 2013)

Menurut Mulyadi (2010), Sistem Informasi Akuntansi adalah organisasi formulir, catatan, dan laporan yang dikoordinasi sedemikian rupa untuk menyediakan informasi keuangan yang dibutukan oleh manajemen guna memudahkan pengelolaan perusahaan. Dengan demikian, pengelolaan sistem informasi merupakan hal yang sangat penting untuk dilakukan. Karena peranan keuangan sangat mempengaruhi suatu perusahaan sehingga laporan keungan sangat penting dan perlu dikembangkan dan diciptakan suatu sistem baik dalam sistem pencatatan maupun pengelolaan data keungan.

Lembaga Karawang peduli merupakan lembaga sosial kemanusiaan yang hadir dan berdiri atas dasar naluri dan keinginan berbagi dengan memberikan solusi. Kegiatannya adalah membantu sesama serta konsen dalam bidang sosial, kemanusiaan dan pendidikan.

Salah satu sistem akuntansi yang digunakan oleh lembaga Karawang peduli adalah sistem penerimaan dan pengeluaran donasi, pada sistem ini menangani penerimaan dan pengeluaran donasi yang terjadi secara rutin. Penerapan sistem penerimaan dan pengeluaran donasi sangatlah penting mengingat kas adalah aset yang mudah berubah dibandingkan dengan aset lain. Dalam pengolahan data penerimaan dan pengeluaran donasi pada Lembaga Karawang Peduli belum mempunyai aplikasi keuangan berbasis web dikarenakan masih menggunakan sistem manual termasuk pengolahan data keuangan dan daftar donatur. Penerimaan dan pengeluaran donasi pada Lembaga Karawang Peduli dicatat dalam buku setelah itu diinput dalam spreadsheet. Pada penelitian sebelumnya mengenai "Sistem Infomasi Penerimaan Donasi pada Yayasan Sahabat Yatim Indonesia menggunakan metode SDLC waterfall berbasis web yang mana pada aplikasinya belum terdapat adanya keterbukaan informasi terkait data penerimaan donasi (Ibrahim, 2017). Permasalahan saat ini pada Lembaga Karawang Peduli yaitu dalam pengolahan data masih menggunakan spreadsheet sehingga dapat menimbulkan terjadinya kekeliruan dalam pemasukan data, terjadinya kehilangan data serta belum adanya sistem pelaporan yang sesuai dengan kebutuhan di Lembaga Karawang Peduli, mekanisme donasi masih melalui media komunikasi atau langsung ketempat Lembaga Karawang Peduli sehingga tidak dapat diakses oleh donatur secara online serta belum adanya keterbukaan informasi keuangan seperti pemasukan dan pengeluaran donasi, Hal ini menciptakan kebutuhan untuk menggunakan sistem data yang terkomputerisasi agar dapat meringankan dan mengefektifkan kinerja karyawan seperti adanya pengolahan dan penyimpanan data yang baik dan cepat, memberikan laporan cepat, tepat serta dapat diakses secara online sehingga memberikan kemudahan akses bagi donatur serta adanya keterbukaan informasi keuangan seperti pemasukan dan pengeluaran donasi serta keterbukaan penggunaan dana donasi. Berdasarkan latar belakang diatas maka penulis mengambil judul "Perancangan Sistem Informasi Penerimaan \& Pengeluaran Donasi Berbasis Web Menggunakan PHp MySQL".

\section{Tinjauan Pustaka}

\section{Pengertian Perancangan Sistem Informasi}

Menurut Anastasia Diana (2010:3), "Sistem merupakan serangkaian bagian yang saling tergantung dan bekerja sama untuk mencapai tujuan tertentu. Suatu sistem pasti 
tersusun dari sub-sub sistem yang lebih kecil yang juga saling tergantung dan bekerja sama untuk mencapai tujuan.

Menurut Anastasia Diana (2010:48), "Perancangan sistem adalah sekumpulan prosedur yang dilakukan untuk mengubah spesifikasi logis menjadi disain yang dapat diimplementasikan ke sistem komputer organisasi". Disain tersebut meliputi disain laporan, formulir, data, dan proses informasi. (A1 Bahra, 2005) Analisis dan perancangan sistem sangat bergantung pada teori sistem umum sebagai sebuah landasan konseptual. Tujuannya adalah untuk memperbaiki berbagai fungsi didalam sistem yang sedang berjalan agar menjadi lebih efesien.

\section{Pengertian Informasi}

Menurut wing wahyu winarno (2016:16), "Informasi adalah data yang sudah diolah sehingga berguna untuk pembuatan keputusan keputusan".

Menurut Sutanta (2004), "Informasi merupakan hasil pengolahan data sehingga menjadi bentuk yang penting bagi penerimanya dan mempunyai kegunaan sebagai dasar dalam pengambilan keputusan yang dapat dirasakan akibatnya secara langsung saat itu juga atau secara tidak langsung pada saat mendatang".

Kualitas dari sebuah informasi sangat dipengaruhi atau ditentukan oleh berbagai hal sebagai berikut :

1. Relevan (relevancy)

Informasi yang berkualitas akan mampu menunjukan relevansi kejadian atau alur dalam bentuk yang kongkrit dan mapu dilaksanakan serta dapat dibuktikan oleh siapa saja.

2. Akurat (accuracy)

Suatu informasi dikatakan berkualitas jika seluruh kebutuhan informasi tersebut telah disampaikan seluruh pesan sudah sesuai dan lengkap seperti kebutuhan user.

3. Tepat Waktu (timelines)

Berbagai proses dapat diselesaikan tepat waktu dan laporan-laporan yang dibutuhkan dapat disampaikan tepat waktu.

4. Ekonomis (economy)

Informasi yang dihasilkan mempunyai daya jual yang tinggi serta mempunyai biaya operasional yang rendah serta memberikan dampak yang luas bagi penggunanya.

\section{Pengertian Penerimaan dan Pengeluaran Kas}

Menurut mulyadi (2016), "pengertian penerimaan kas adalah kas yang diterima perusahaan baik yang berupa uang tunai maupun surat-surat berharga yang mempunyai sifat dapat segera digunakan, yang berasal dari transaksi perusahaan maupun penjualan tunai, pelunasan piutang, atau transaksi lainnya yang dapat menambah kas perusahaan".

Menurut Somarso (2002), "pengertian kas adalah sebagai organisasi formulir, catatan dan laporan yang dibuat untuk melaksanakan kegiatan pengeluaran kas untuk mempermudah setiap pembiayaan pengelolaan perusahaan”.

\section{Metode Penelitian}

Metode penelitian yang digunakan adalah metode SDLC Waterfall yaitu suatu metodologi perangkat lunak yang mengusulkan pendekatan kepada perangkat lunak sistematik dan sekuensial pada Project Planing Phase, Analysis Phase, Design Phase, Implementation Phase, dan Support Phase (Satzinger, et al, 2010).

\section{Project Planning Phase}

Tahap ini dilakukan penelitian atau riset terlebih dahulu untuk mendapatkan data serta informasi yang terkait. Adapun tahapan dalam tahap ini adalah sebagai berikut :

Tabel 1. Tahapan Project Planning Phase

\begin{tabular}{|c|c|c|}
\hline No & Tahapan & Deskripsi \\
\hline 1. & $\begin{array}{l}\text { Identifikasi } \\
\text { Masalah }\end{array}$ & $\begin{array}{l}\text { Menentukan masalah- } \\
\text { masalah yang timbul } \\
\text { mengenai Penerimaan dan } \\
\text { Pengeluaran donasi pada } \\
\text { Lembaga Karawang } \\
\text { Peduli untuk membangun } \\
\text { sistem. }\end{array}$ \\
\hline 2. & $\begin{array}{l}\text { Pengumpulan } \\
\text { Data }\end{array}$ & $\begin{array}{lr}\text { Melakukan studi litarature } \\
\text { melalui jurnal } & \text { penelitian } \\
\text { sebelumnya } & \text { dan } \\
\text { melakukan } & \text { observasi } \\
\text { dengan } & \text { proses } \\
\text { wawancara. } & \end{array}$ \\
\hline 3. & $\begin{array}{l}\text { Menganalisis } \\
\text { Teori }\end{array}$ & $\begin{array}{lr}\text { Menganalisis } & \text { sistem } \\
\text { informasi penerimaan dan } \\
\text { pengeluaran } & \text { donasi }\end{array}$ \\
\hline
\end{tabular}




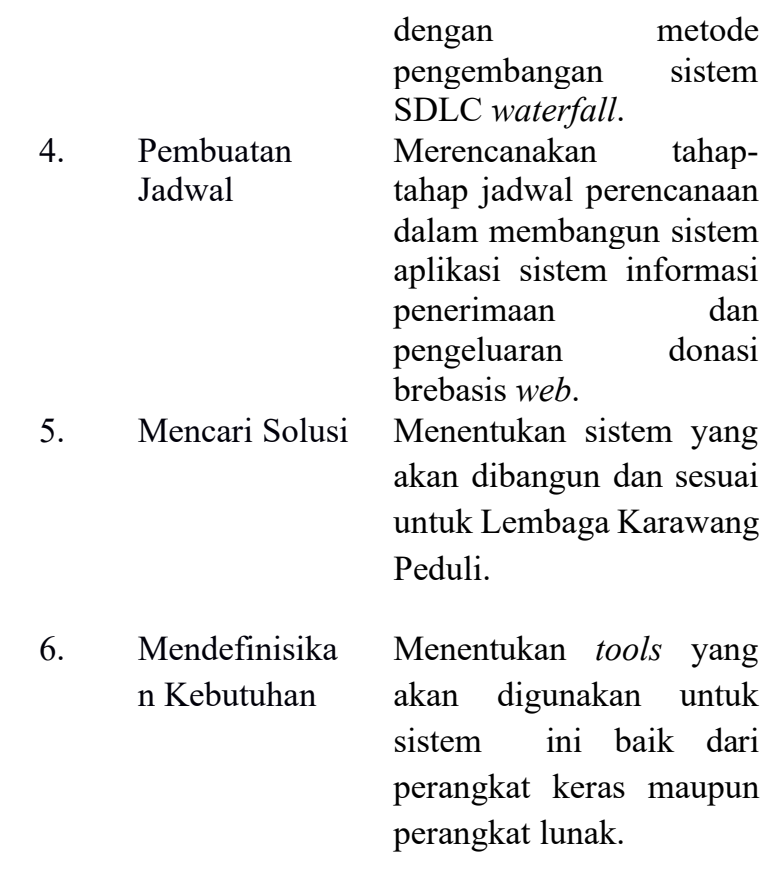

\section{Analysis Phase}

Analisis phase adalah tahap untuk memahami dan mendokumentasikan kebutuhan bisnis dan persyaratan pengolahan sistem baru, dalam tahap analisis akan didefinisikan dalam bentuk grafis dari analisa sistem ajuan dan rincian sebagai berikut :

\section{Analisis Sistem Ajuan}

Tahap ini yaitu mempelajari sistem yang ada dan menganalisis bidang masalah dengan menggunakan Object Oriented Analysis (OOA), sehingga dapat diperoleh dari pemahaman menyeluruh terhadap masalah-masalah serta manfaat yang akan diperoleh. Adapun tahapan dari analisis tersebut yaitu :

- System Activities (Actor Description, Use Case Description, Use Case Diagram, And Skenario Use Case).

- Class Diagram (Class Definition And Class Relation).

- Object Interaction (Sequence Diagram).

- Object Behavior (Activity Diagram).

\section{Design Phase}

Tahap ini dilakukan analisis terhadap desain aplikasi untuk membuat aplikasi menggunakan object oriented design (OOD), seperti:

1. Desain proses

2. Desain database

3. Desain antarmuka

\section{Implementation Phase}

Implementation phase adalah tahap pembuatan program termasuk penulisan kode program, pengetesan program secara terus menerus untuk mencari kesalahan yang terjadi pada program yang dibuat, kemudian meletakkan sistem untuk dioperasikan.

Penulisan kode program dilakukan dengan teknik Object Oriented Programming (OOP) secara modular sehingga akan mempermudah dalam memodifikasi kode yang sudah ada. Dapat menyederhanakan kompleksitas dengan memungkinkan programmer untuk mendefinisikan sebuah sistem besar dan kompleks menggunakan set yang lebih kecil dari objek yang saling terkait. Pada tahap ini dilakukan beberapa tahapan antara lain :

1. Instalisasi Sistem

Menjelaskan tahapan-tahapan dilakukannya proses instalasi aplikasi pada komputer atau laptop.

2. Pengujian Terhadap Sistem

Pengujian sistem dilakukan dengan dua tahap yaitu pengujian white box dan black box. Pengujian white box dilakukan pada pengecekan perancangan sistem, mengetahui cara kerja sistem secara internal agar operasioperasi internal pada sistem sesuai dengan spesifikasi yang telah ditetapkan. Sedangkan pengujian black box yaitu suatu pendekatan untuk menguji apakah sistem setiap fungsi didalam program dapat berjalan dengan benar. Proses yang dilakukan dalam pengujian ini adalah sebagai berikut :

1. Fungsi-fungsi yang tidak benar, baik input maupun output.

2. Kesalahan interface.

3. Kesalahan dalam stuktur data atau akses database. 


\section{Support Phase}

Setelah sistem yang di bangun rampung, langkah terakhir yang dilakukan memperbaiki dan meningkatkan sistem secara berkala. Dalam fase program ini juga dilakukan uji kelayakan sistem yang dibuat seperti input, interface, proses dan memindahkan data secara berkala.

\section{Hasil dan Pembahasan}

\section{a. Project Planning Phase}

Tahapan project planning phase menghasilkan data pada tabel 2 sebagai berikut:

Tabel 2. Project Planning Phase

\begin{tabular}{lll}
\hline No & Tahapan & Deskripsi \\
\hline 1. & Identifikasi & Dengan dibangunnya \\
& Masalah & aplikasi ini akan \\
& mempermudah pembuatar \\
& laporan penerimaan dan \\
& pengeluaran donasi yang \\
& akurat dan tepat waktu saal \\
& dibutuhkan, \\
& dapat memberikar \\
& kemudahan bagi donator \\
& pada saat akan memberikan \\
& donasi dan memberikar \\
& keterbukaan pada donatur \\
& terkait donasi.
\end{tabular}

2. Pengumpulan data Melalui studi literature jurnal-jurnal penelitian sebelumnya dan melakukan observabi dengan proses wawancara pada Lembaga Karawang Peduli terkait dengan penerimaan dan pengeluaran donasi.

3. Menganalisis Dapat membangun

\begin{tabular}{rrr}
\hline teori & sistem & informasi \\
& penerimaan & dan \\
pengeluaran & donasi \\
& menggunakan & metode \\
& pengembangan & sistem
\end{tabular}

SDLC waterfall (Satzinger, Jackson, \& Burd，2010) dan OOP.

4. Pembuatan jadwal Penelitian dilakukan di Lembaga Karawang Peduli dari bulan Februari sampai Juli.

5. Mencarai solusi

Solusi dari masalah yang ada pada Lembaga Karawang Peduli adalah dengan membangun sistem informasi penerimaan dan pengeluaran donasi berbasis web menggunakan PHP dan MySQL dengan metode pengembangan sistem SDLC (System Development Life Cycle) waterfall serta OOP.

6. Mengidentifikasi Kebutuhan

Spesifikasi Hardware:

1. Monitor standar

2. Hardisk $500 \mathrm{~GB}$

3. RAM $2 \mathrm{~GB}$

4. Printer Spesifikasi Software

5. Sistem operasi windows,

6. Notepad ++,

7. Geany,

8. Star UML,

9. PHP, dan Mysql

\section{Analysis Phase \\ 1) Analisa Sistem Berjalan}

Sistem berjalan merupakan sistem yang sedang berlangsung dilapangan penelitian, yang menjadi intruksi kerja ditempat penelitian tersebut, dalam hal ini tempat penelitian tersebut adalah Lembaga Karawang Peduli yaitu mengenai penerimaan dan pengeluaran donasi.

\section{2) Sistem Berjalan Penerimaan}

Deskripsi dari tahapan analisis berjalan penerimaan donasi akan ditujukan pada tabel berikut: 
Tabel 3. Penerimaan

\begin{tabular}{|c|c|c|}
\hline No & Proses & Deskripsi \\
\hline 1. & $\begin{array}{l}\text { Donatur } \\
\text { Datang ke } \\
\text { Lembaga }\end{array}$ & $\begin{array}{l}\text { Donatur datang langsung ke } \\
\text { Lembaga Karawang Peduli. }\end{array}$ \\
\hline 2. & $\begin{array}{l}\text { Donatur } \\
\text { Mengisi } \\
\text { Buku } \\
\text { Tamu }\end{array}$ & $\begin{array}{l}\text { Bagian Keuangan memberikan } \\
\text { buku tamu yang akan diisi oleh } \\
\text { donatur. }\end{array}$ \\
\hline 3. & $\begin{array}{l}\text { Donatur } \\
\text { Memberik } \\
\text { an Donasi }\end{array}$ & $\begin{array}{ll}\text { Setelah mengisi buku tamu, } \\
\text { donatur } & \text { memberikan } \\
\text { donasinya. } & \end{array}$ \\
\hline 4. & $\begin{array}{l}\text { Donatur } \\
\text { Menerima } \\
\text { kuitansi }\end{array}$ & $\begin{array}{l}\text { Bagian Keuangan memberikan } \\
\text { kuitansi kepada donatur. }\end{array}$ \\
\hline 5. & $\begin{array}{l}\text { Bagian } \\
\text { Keuangan } \\
\text { Mencatat } \\
\text { Transaksi }\end{array}$ & $\begin{array}{l}\text { Bagian Keuangan mencatat } \\
\text { bukti transaksi donasi pada } \\
\text { form penerimaan donasi. }\end{array}$ \\
\hline 6. & Laporan & $\begin{array}{l}\text { Bagian Keuangan akan } \\
\text { membuat laporan penerimaan } \\
\text { donasi yang bersumber dari } \\
\text { dokumen-dokumen seperti } \\
\text { daftar donatur, daftar } \\
\text { penerimaan donasi dan kuitansi } \\
\text { penerimaan. Kemudian laporan } \\
\text { tersebut akan diserahkan } \\
\text { kepada Direktur untuk ditanda } \\
\text { tangani dan diarsipkan. }\end{array}$ \\
\hline
\end{tabular}

\section{3) Sistem Berjalan Pengeluaran}

Deskripsi dari tahapan analisis berjalan pengeluaran donasi akan ditujukan pada tabel berikut:

Tabel 4. Pengeluaran

\begin{tabular}{lllrr}
\hline No & Proses & Deskripsi & \\
& & & & \\
\hline 1. & Penyerahan & Bentuk & bukti & transaksi \\
& Bukti & berupa kuitansi & serta \\
& Transaksi & menyerahkan ke & bagian \\
& Pengeluaran & keuangan. & & \\
& Donasi & & & \\
& & &
\end{tabular}
2. Bukti Data yang digunakan untuk Transaksi membuat laporan.
Pengeluaran
3. Input
Transaksi
Proses pemasukan data transaksi pada form pengeluaran.

\section{Bagian Bagian Keuangan mencatat} Keuangan bukti transaksi donasi.

Mencatat

Transaksi

5. Laporan

Bagian Keuangan akan
membuat pengeluaran donasi yang bersumber dari dokumendokumen seperti daftar donatur, pengeluaran donasi dan. Kemudian laporan tersebut akan diserahkan kepada Ketua untuk ditanda tangan dan diarsipkan.

\section{c. Analisa Sistem Ajuan}

Tabel 5. Sistem Ajuan

\begin{tabular}{|c|c|c|}
\hline No & Aktor & Deskripsi \\
\hline 1 & $\begin{array}{l}\text { Bagian } \\
\text { Keuangan } \\
\text { (Admin) }\end{array}$ & $\begin{array}{lr}\text { Bagian } & \text { Keuangan } \\
\text { merupakan pengguna } \\
\text { sistem yang memiliki hak } \\
\text { akses penuh terhadap } \\
\text { sistem dan mampu } \\
\text { megakses semua proses } \\
\text { yang ada di dalam sistem. }\end{array}$ \\
\hline 2. & Direktur & $\begin{array}{l}\text { Pimpinan merupakan } \\
\text { pengguna sistem yang } \\
\text { memiliki hak akses untuk } \\
\text { melihat data donatur dan } \\
\text { melihat } \\
\text { penerimaan laporan } \\
\text { pengeluaran donasi. }\end{array}$ \\
\hline 3. & Donatur & $\begin{array}{l}\text { Donatur merupakan } \\
\text { pengguna sistem yang } \\
\text { memiliki hak akses untuk }\end{array}$ \\
\hline
\end{tabular}


registrasi donasi, transaksi donasi dan unduh file laporan donasi dan pengeluaran donasi.

\section{d. Usecase Diagram}

Tabel 6. Deskripsi Use Case

\begin{tabular}{llll}
\hline No & Use Case & Deskripsi \\
\hline 1 & Login & Merupakan proses masuk \\
& & kedalam sisitem dengan \\
& & memasukan id user dan \\
& & password untuk mendapatkan \\
& & hak akses terhadap sistem.
\end{tabular}

2 Registrasi Merupakan proses donatur Donatur melakukan registrasi data diri melalui form pada sistem.

3 Transaksi Merupakan proses dimana Donasi donatur melakukan proses pengiriman transaksi donasi.

4 Unduh Merupakan proses dimana Laporan donatur mengunduh hasil laporan donasi.

5. Unduh Merupakan proses dimana Laporan donatur mengunduh hasil Donasi laporan donasi.

6. Unduh Merupakan proses dimana Laporan donatur mengunduh hasil Pengeluaran laporan donasi pengeluaran

7 Kelola data Merupakan proses dimana Pengguna bagian keuangan dapat mengelola data pengguna seperti : edit data pengguna dan hapus data pengguna.

8 Lihat Data Merupakan dimana bagian Donatur keuangan untuk melihat semua data donatur.

9 Konfirmasi Merupakan proses dimana Transaksi bagian keuangan Penerimaan mengonfirmasi transaksi masuk yang telah dilakukan oleh donatur.

10 Kelola Data Merupakan proses dimana Pengeluaran bagian keuangan dapat mengelola pengeluaran donasi.

11 Laporan Merupakan proses dimana mencetak laporan penerimaan dan pengeluaran donasi per periode tanggal, bulan dan tahun sesuai yang dibutuhkan.

12 Laporan Merupakan proses dimana Penerimaan bagian keuangan mencetak laporan penerimaan donasi per periode tanggal, bulan dan tahun sesuai yang dibutuhkan.

13 Laporan Merupakan proses dimana Pengeluaran bagian keuangan mencetak laporan pengeluaran donasi per periode tanggal, bulan dan tahun sesuai yang dibutuhkan.

14 Lihat Data Merupakan proses dimana Donatur Direktur dapat melihat daftar donatur.

15 Laporan Merupakan proses dimana Penerimaan Direktur dapat melihat laporan penerimaan donasi.

16 Laporan Merupakan proses dimana Pengeluaran Direktur dapat melihat laporan pengeluaran donasi.

17 Logout Merupakan proses keluar dari sistem. 


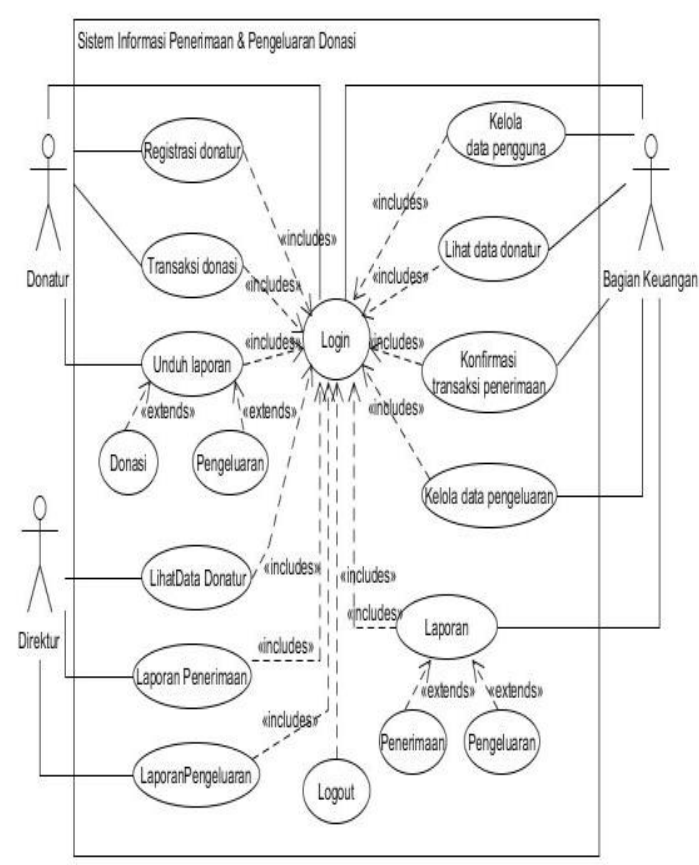

Gambar 1. Use case diagram

\section{e. Class Diagram}

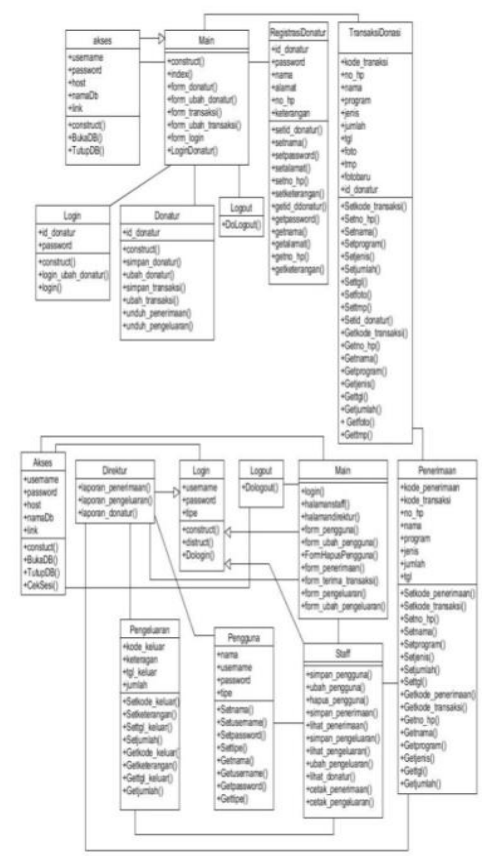

Gambar 2. Class diagram

\section{f. Sequence Diagram}

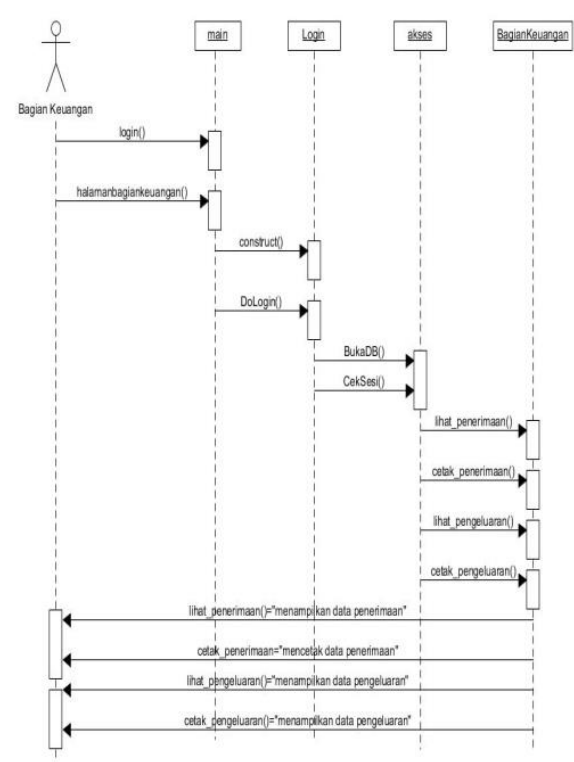

Gambar 3. Sequence diagram

\section{g. Activitv Diagram}

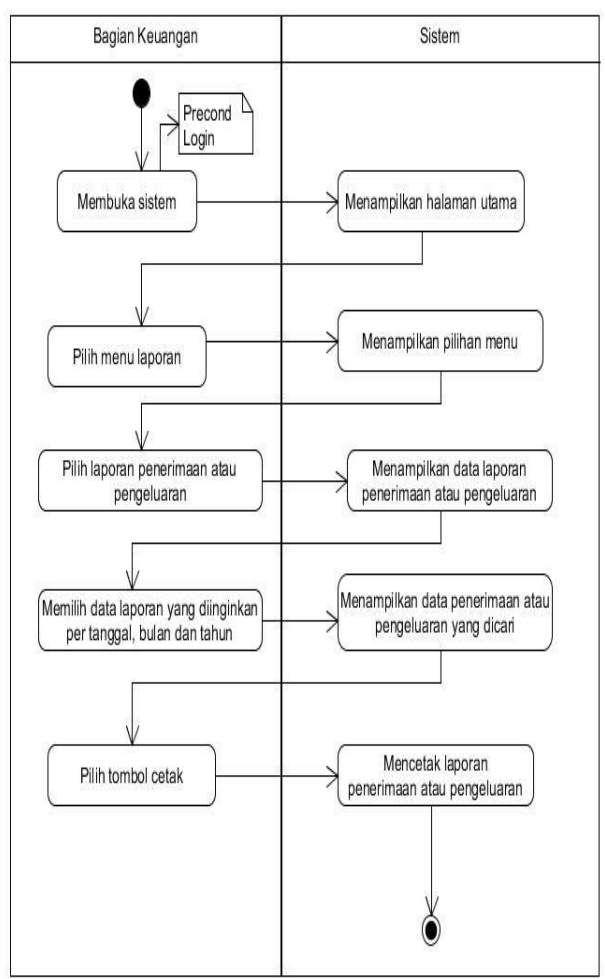

Gambar 4. Activity Diagram Kelola Laporan 


\section{h. Design Phase}

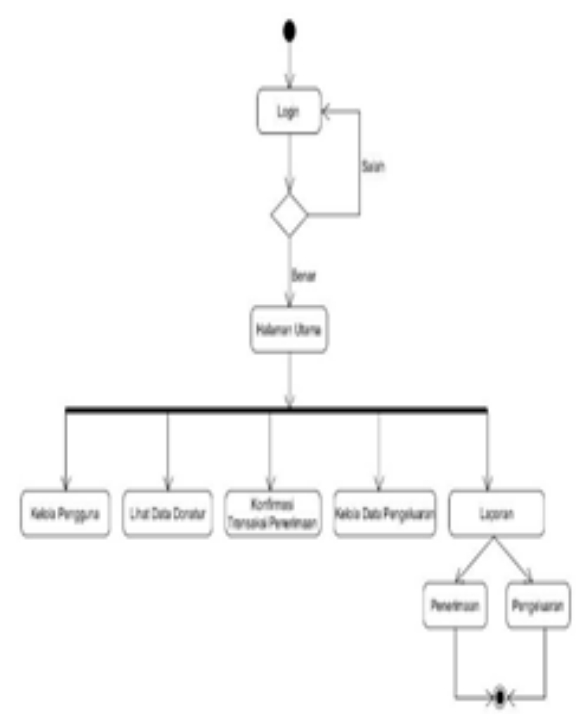

Gambar 5. Design Phase

\section{i. Design Interface Login}

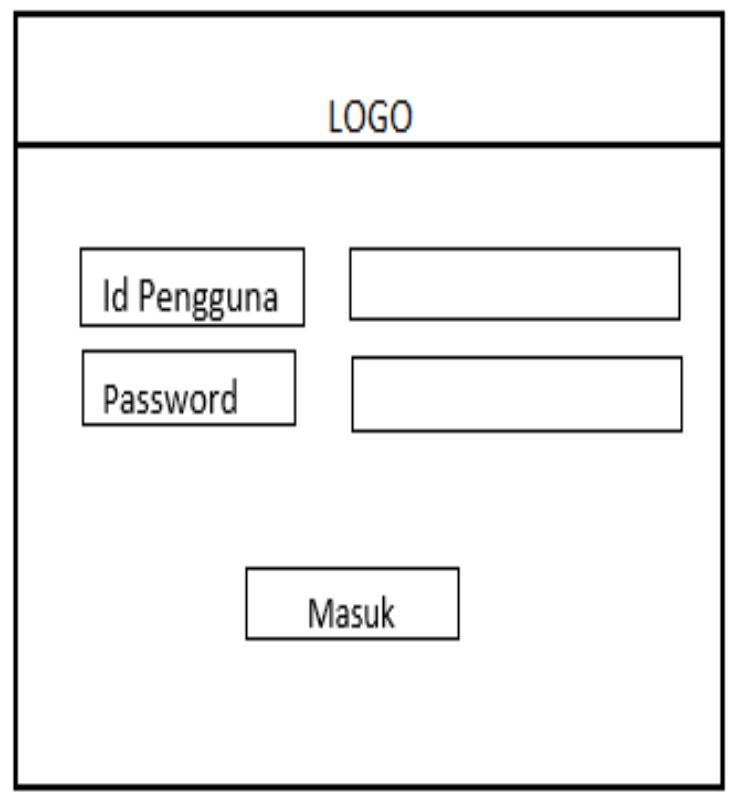

\section{j. Design Database}

Berikut adalah rancangan database yang digunakan pada sistem :
Tabel 6. Deskripsi Design Database

\begin{tabular}{lll}
\hline No & Nama Tabel & Keterangan \\
\hline 1. & akses & Master \\
2. & donatur & Master \\
3. & penerimaan & Transaksi \\
4. & pengeluaran & Transaksi \\
5. & pengguna & Master \\
6. & transaksi_donasi & Transaksi \\
\hline
\end{tabular}

\section{k. Tampilan Halaman Login}

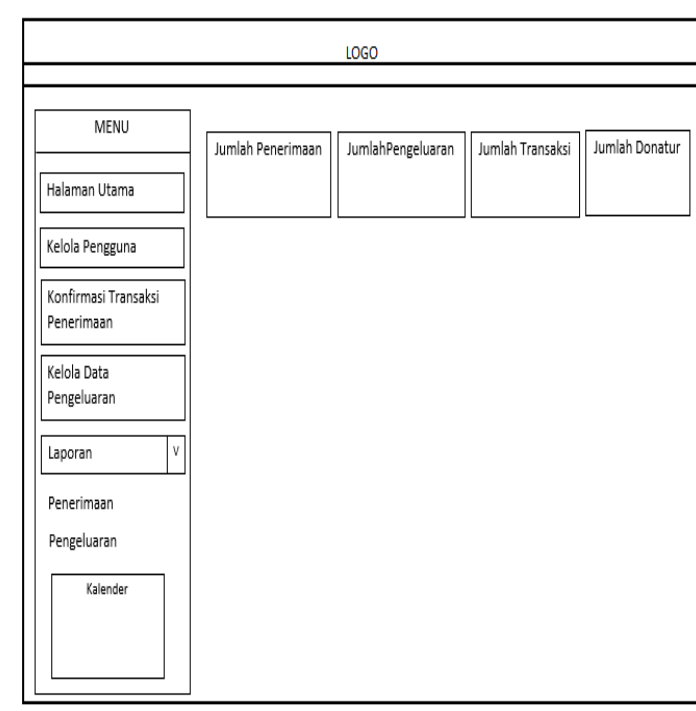

Gambar 7. Design Interface Halaman Utama Bag. Keuangan

\section{Implementation Phase}

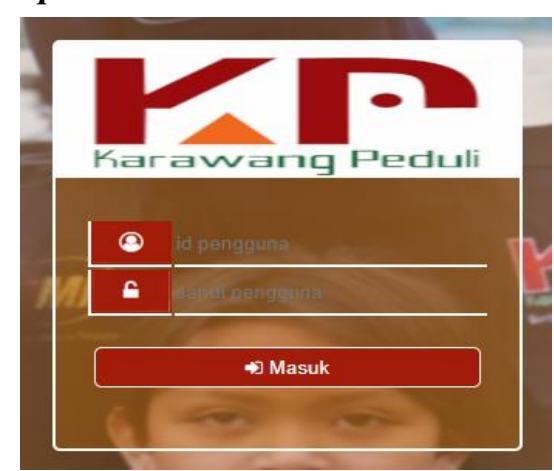

Gambar 8. Tampilan form Login 


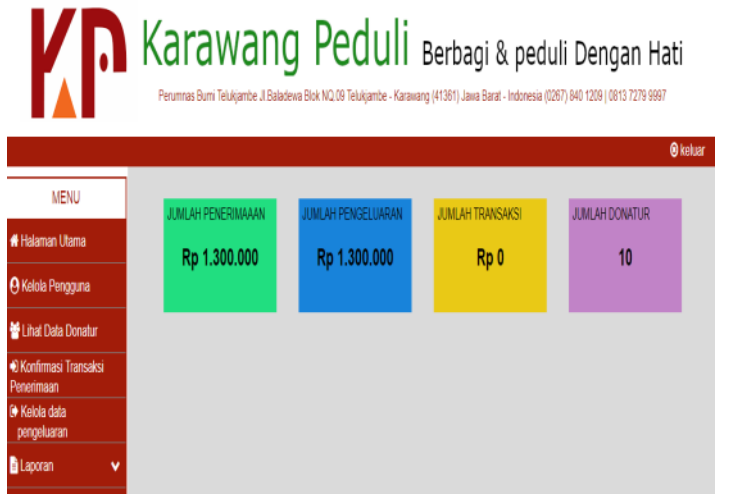

Gambar 9. Tampilan halaman utama

\section{Kesimpulan dan Saran}

\section{Kesimpulan}

Berdasarkan hasil penelitian yang penulis lakukan mengenai sistem informasi penerimaan dan pengeluaran, maka penulis dapat mengambil beberapa kesimpulan sebagai berikut :

1. Dengan dibuatnya sistem informasi penerimaan dan pengeluaran donasi berbasis web dapat memperlancar dalam proses pengelolaan data donatur, pembuatan laporan penerimaan dan pengeluaran donasi lebih sistematis dan terorganisir saat pengaksesan data dan pemrosesan data yang masuk kedalam sistem sehingga meminimalisir terjadinya kekeliruan dalam memasukan data.

2. Dengan adanya sistem tersebut maka dalam melakukan penerimaan dan pengeluaran donasi dapat diakses secara online, sehingga memudahkan dari berbagai pihak dari segi penyampaian informasi terkait data penerimaan dan pengeluaran donasi.

3. Dengan membangun sistem informasi penerimaan dan pengeluaran donasi berbasis web penyampaian laporan informasi terkait data penerimaan dan pengeluaran donasi bisa dilakukan secara otomatis, yaitu dengan menginformasikan penerimaan dan pengeluaran di dalam website sehingga setiap saat donatur dan direktur bisa mendapatkan informasi kapanpun dan dimanapun berada.

\section{Saran}

Berdasarkan kesimpulan diatas, masih banyak yang harus diperbaiki, agar kedepannya sistem ini dapat dikembangkan lagi. Saran dari penulis adalah:

1. Penambahan fungsi-fungsi yang dapat ditambahkan dan dikembangkan dalam sistem ini, pengembangan tersebut tentunya ditujukan untuk meningkatkan kualitas sistem informasi penerimaan dan pengeluaran donasi yang sesuai dengan kebutuhan.

2. Dalam segi interface, aplikasi masih nampak sederhana dan harus mendapatkan desain yang lebih baik.

3. Dengan adanya perancangan sistem baru yang sudah terkomputerisasi, perlu diberikan sosialisasi pelatihan kepada karyawan berkaitan dengan penggunaan sistem baru.

\section{Daftar Pustaka}

Anatasia diana dan lilis Setiawati. 2010. Sistem Informasi Akuntansi. Penerbit. CV Andi Offset Yogyakarta

AS. Rosa dan M. Shalahuddin. 2014. Rekayasa Perangkat Lunak Terstruktur dan Berorientasi Objek. Bandung: Informatika.

Buana, I Komang Setia. 2011. Jago Pemrograman Php. Dunia Komputer. Jakarta.

M.Rudianto, Arief. 2011. Pemrograman Web Dinamis Menggunakan PHP dan Mysql. Yogyakarta. Andi: Yogyakarta.

Mulyadi. 2010. Sistem Akuntansi. Jakarta: Salemba Empat.

Nugroho, Bunafit. 2013. Dasar Pemrograman Web Php-Mysql dengan Dreamweaver. Yogyakarta. Gaya Media.

Pressman, Ph. D. Roger. S. 2010. Pendekatan Praktisi Rekayasa Perangkat Lunak. Edisi. 7. Penerbit. Andi.Yogyakarta.

Satzinger, J, W, Jackson, R. B \& Burd. S. D. 2010. System Analysis and Design in A Changing World. Boston, Ma : Course Technology. 
Subhan, Mohamad. 2012. Analisa Perancangan Sistem. Jakarta : Lentera Ilmu.

Sutabri Tata. 2012. Analisa Sistem Informasi. Yogyakarta. Andi.

Wing Wahyu Winarno. 2006. Sistem Informasi Akuntansi. Penerbit UPP STIM YKPN Yogyakarta

Yakub. 2012. Pengantar Sistem Informasi. Yogyakarta. Graha Ilmu. 